\title{
AN EXPLORATION OF FACTORS AFFECTING THE Process of English Language Course Design FROM THE PERSPECTIVES OF TEACHERS IN A College ConTeXT
}

\author{
Iman Alkhalidi \\ Al Buraimi University College, Oman
}

\begin{abstract}
Course design is viewed as the foundation of the curriculum development process that contributes to shaping and guiding the subsequent stages of teaching and assessment. The study is a qualitative case study that aims to explore the factors that have influential effects on the efficiency of the process of course design from the perspectives of teachers who design their courses in a college context in Oman. It also aims to explore how these factors affect course design. The study draws on the philosophy and epistemology of the interpretive paradigm that shapes and guides its methodology, methods of data collection, and analysis of data. Findings of study show that there is a variety of factors that affect course design. These factors canbe categorized into two major categories, Student and Institutional Factors. Based on the findings of data analysis, the study offers a number of implications that are of value for those who are involved in the process of course design, particularly in the current context.
\end{abstract}

\section{KEYWORDS}

Course design, Curriculum development, Factors and challenges, Student and Institutional Factors

\section{INTRODUCTION}

Course design is viewed as the foundation of the curriculum development process that contributes to shaping and guiding the subsequent stages of teaching and assessment. In her emphasis on the importance of course design, Toohey (2002) points out that much of the effectiveness of teaching lies in course design. Likewise, Graves (2000) confirms the crucial role that course design plays in not only comprising the content of a particular course, but also in shaping classroom methodology. Furthermore, Whetten (2007) argues that a well-designed course is like a guiding 
This study deals with the process of course design within the domain of TESOL curriculum at a tertiary institution. In Oman, where this study takes place, the field of English language teaching has witnessed certain modifications and reformations in order to fulfill the needs of learners in accordance with the requirements of the global trends (Al Jardani, 2012; Abdel-Jawad and Abu Radwan, 2011; Al Issa, 2007; 2006; carol and Palermo, 2006; Al Jadidi,2009). Curriculum development has undergone certain modifications across all stages: course design, teaching and learning, and students' assessment (Richards, 2007, MacKernan, 2008, Pennycook, 1999). At the level of course design, which is the primary concern of this study, certain changes took place in the selection of materials and content of a course and the development of goals and objectives.

The literature on curriculum or course design has provided considerable work on identifying, conceptualizing, and analyzing course design through providing several models and approaches. However, there is a notable gap in the literature with regard to examining the role of teachers in designing the courses they teach and exploring factors that have an influential impact on the efficiency of the process. Moreover, most of research studies are concerned with addressing single components of course design, particularly in relation to syllabus design, material development, and students' needs. Therefore, this study intends to fill in this gap in our TESOL context, particularly in the Arabian Gulf region to approach further understanding and exploration of the participants' perspectives and experiences based on reality and naturalism of their professional context. It is expected through this investigation to understand how teacher participants design their courses within the considerations and circumstances of their professional context.

In particular, this study aims to investigate and explore what factors that have the greatest impact on course design and how they affect the whole process. Exploring these factors helps the researcher to approach a holistic understanding of the course design process in order to provide a set of implications for improving course design in this professional context. In light of the purpose and aims of the study and its concern with investigating the issue from the perspectives of teachers and students, the current study addresses the following questions:

Q.1 What factors have a major impact on designing courses from the perspectives of teachers?

Q.2 How do these factors impact the process of course design?

\section{Literature REVIEW}

\subsection{Course Design: an Overview}

Course design is defined by Hutchinson and Waters (1991, p.65) as "an integrated series of teaching-learning experiences, whose ultimate aim is to lead the learners to a particular state of knowledge". Likewise, Graves (2008, p.147) defines course design as "a teaching/learning experience that occurs over a specific time with a specific focus". However, Graves $(2000 ; 1996)$. argues that the terms 'curriculum' and 'course' must be viewed distinctively. She points out that the term curriculum must be viewed in the broadest sense "as the philosophy, purposes, design, and implementation of a whole program" (1996, p.3). She further argues that the two terms, course and curriculum cannot be identical since curriculum requires some features that are out of teachers' concerns such as "'societal needs analysis, testing for placement purposes or program wide evaluation" (ibid). Similarly, Richards (2013, p.6) states that "The term Curriculum is used to refer to the overall plan or design for a course and how the content for a course is transformed into a blueprint for teaching and learning which enables the desired learning outcomes to be achieved". 
In her book (2000) Graves provides a detailed framework that portrays course design as a process that comprises a number of components or factors such as defining the context, articulating beliefs, formulating goals and objectives, etc. Examining the framework below (Figure 1) we can notice that "there is no hierarchy in the processes and no sequence in their accomplishment" (Graves, 2000, p.3). This means that a teacher can start with any component in the framework on the basis of his beliefs and contextual understandings that are considered as basic components. Therefore, they are stated at the bottom of the chart "to serve as the foundation of the other processes" (p.3).

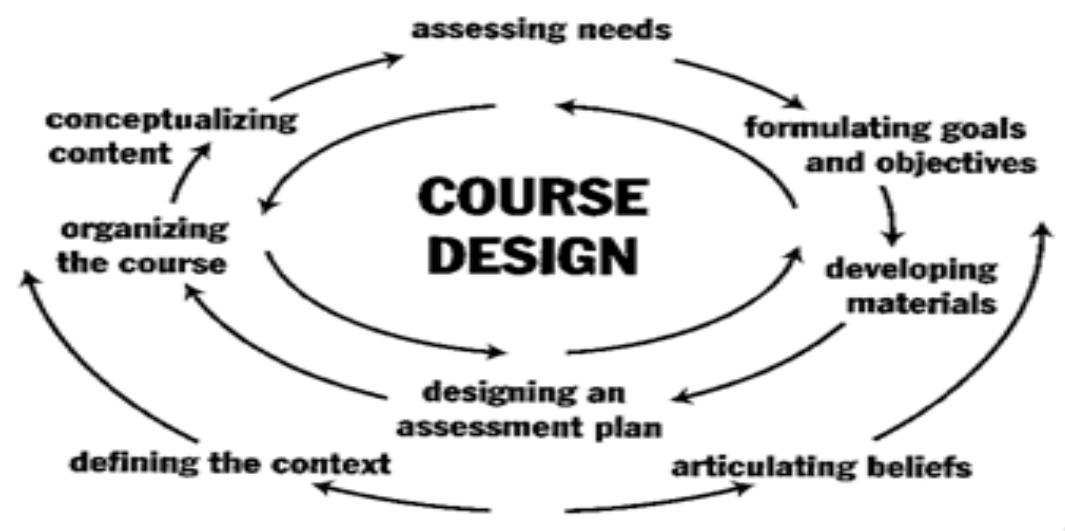

Figure 1. A Framework of Course Development Process (Adapted from Graves, 2000)

\subsection{Factors Affecting Course Design from Theoretical Perspectives}

In practice, course designers and teachers must consider a few questions such as which element to start with, how to arrange the elements in a principled manner, and what learners need, and so on. For this purpose, there are several factors that must be considered for designing courses in a principled way. This section, therefore, presents a set of factors that form the basis of designing a relevant, coherent, and meaningful course.

\subsubsection{Defining the context}

"Defining the context" (Graves, 2000) or "situation analysis" (Richards, 2007) is viewed as a crucial factor in course design. Graves considers it as the foundation of course design. Similarly, other specialists in course design (like Dubin and Olishtain, 1987; Yalden, 1987) consider the notion of context as a pre-stage factor that has to be considered before processing course design. According to Graves, designing a course "is a grounded process" which means that "when you design a course, you design it for a specific group of people, in a specific setting, or for a specific amount of time, in short for a specific context" (2000, p. 15). Defining the context helps a teacher to gain more information which contributes to making decisions about what and how to teach.

In curriculum design, context might be viewed at the specific level and at the broadest level. At the specific level, context refers to a particular teaching learning setting represented by the classroom, the school, the institution, a specific group of teachers and students, and specific learning topics (Graves, 2008; 2000; 1996). It also involves issues to be considered at the course level such as the level of students, the length of the course, and the setting where the course is taking place. At the broadest level, viewing context means more than considering these factors, but other factors that are social, cultural, political, and psychological that might affect the learning situation. 
Richards (2007) uses the term "situation analysis" instead of "defining context". He considers "situation analysis" as a procedure used to analyze the factors that determine the success of a language program. He refers to three factors that determine the effectiveness of curriculum development: institutional factors, teacher factors, and learner factors (for further discussion see Richards, 2007).

\subsubsection{Articulating Beliefs}

Generally, in the literature on education the term belief is defined by Borg (2001, p.186)as "a proposition which may be consciously or unconsciously held, is evaluative in that it is accepted as true by the individual, and is therefore imbued with emotive commitment; further it serves as a guide to thought and behavior". In relation to course design, Graves (2000) argues for the consideration of the value of beliefs. She refers to the concept of beliefs as "articulating beliefs" and considers it as the foundation of course design. Her argument is based on the rationale that articulating beliefs guides teachers to design and implement their courses effectively since their beliefs are based on their previous and present experience in their professional context. Graves further points out that teacher's beliefs affect every stage of course design. "They may not always be present in your thinking, but they underlie the decisions you take". (2000, p. 33). It is worth remarking that this concept is of high value in this study since the latter draws on investigating teachers and students' beliefs in a particular context.

With regard to the question how teachers articulate their beliefs in designing language courses, Graves recommends adopting Stern's framework that involves four aspects:

- Beliefs about language

- Beliefs about the social context of language

- Beliefs about language and learners

- Beliefs about teaching

Each of those aspects involves certain issues to consider (for further details see Graves, 2000, pp. 28-32).

\subsubsection{Needs Assessment}

Needs analysis or needs assessment is defined by Graves as "a systematic and ongoing process of gathering information about students' needs and preferences, interpreting the information, and then making course decisions based on the interpretation in order to meet the needs" (2000, p. 98). Needs analysis is viewed as the basic component in course design upon which the other components such as the goals of the course, activities, topics, and assessments and evaluations are built (Richards, 2007; Fatihi, 2003; Brown, 1995; Jordan, 2004; Brindley, 1989). The value of its importance lies in its relatedness to students' involvement in the process of course design. It is based on the belief that learning is a teacher student interaction, rather than merely a matter of learners' "absorbing preselected knowledge" (Graves, 2000, p. 98).

As teachers we need to know what kind of information we have to gather about our students. For this, Graves provides a very useful and simple illustration where the information is organized according to both the present status of the students and the future (goals of a course). Regarding the present status, the information involves the level of the learners' language proficiency, the level of the learners' cultural competence, learners' interest, preferences, and attitudes. The information about their future involves their goals and expectations, the learning context, types of communicative skills and tasks they need to perform, and language aspects they will use. 
"What needs to be learned" (Nation and Macalister, 2010, p. 24) is a crucial issue within the notion of needs analysis. For this purpose, there are three approaches underlying the type of needs to be focused on. One approach is by Munby called 'target-situation analysis' that focuses on "the students' needs at the end of a language course, and target-level performance" (Jordan, 2004). The second approach is advocated by Richterich and Chancerel called "present-situation analysis" concerned with "the students' state of language at the beginning of the language course" (Jordan, 2004, p. 24). The third approach is advocated by Hutchinson and Waters (1991) called the 'learning-centered approach'. In light of this approach, Hutchinson and Waters make a distinction between 'target needs' and 'learning needs'. Target needs are concerned with "what the learner needs to do in the target situation", whereas learning needs are concerned with what the learner needs to do in the learning situation". Furthermore, Hutchinson and Waters analyze target needs into three types: 'necessities', 'lacks', and 'wants'. Below is a brief definition of each type:

Necessities-involve what is important for students to know in order to act effectively in the target situation.

Lacks-involve any gaps between what the students already know and the target situation.

Wants-involve what the students wish to learn.

Learners' needs can also be categorized in terms of 'objective needs 'and 'subjective needs' (Hutchinson and Waters, 1991). Both 'necessities' and 'lacks' fit to objective needs, while 'wants' fit into subjective needs (Jordan, 2004). The crucial issue, in this respect, concerns learners' subjective needs that might conflict with teachers or course designers' beliefs (Jordan, 2004). For example, a language course may focus on writing, while students are concerned with improving their speaking skills. In this regard, Jordan says "there is no easy answer to this, but it is important that these views are taken into consideration" (2004, p. 26). McDonough (cited in Jordan, 2004) points out that in this case, teachers need to take into consideration their students' views and attitudes along with needs analysis. This requires "the ability to be flexible and to adapt a course program" (2004, p.26).

In order to collect information about students for needs analysis, Graves (2000) and Richards (2007) provide a set of practical procedures involving 'questionnaires' 'interviews', 'charts', 'lists', 'writing activities', 'group discussions', etc. (for further discussion of these procedures see Graves, 2000 and Richards, 2007).

Among the key factors in course design is the one of content (Graves, 2000; 1996; Nation and Macalister, 2010). The element of content is referred to in different terms such as “conceptualizing content" (Graves, 2000), syllabus design (Yalden, 1987; Dubin and Olishtain, 1987), "selection and sequencing units of a particular subject" (Nation and Macalister, 2010), while Richards (2013) refers to it in terms of "input". Graves, however, prefers the term "conceptualizing content" rather than the traditional term syllabus design because she views it as a " conceptual process" (2000, p.39) that requires from a teacher to figure out what aspects of language to teach, emphasize, and integrate on the basis of teacher's thoughts and beliefs.

The content of a language course is also considered to be the base of the whole process of course designs, upon which the next stage that is the process (methodology) will be established which in turn contributes to achieving the outcomes of the program. Similarly, Graves $(2000 ; 1996)$ considers it as the backbone of designing a course. The following discussion provides a brief outline of the process of conceptualizing content adapted from Graves (2000). 


\section{"What does it mean to conceptualize content?"}

In response to this question, Graves states that "conceptualizing content is a multifaceted process which involves:

- Thinking about what you want your students to learn in the course, given

- who they are, their needs, and the purpose of the course.

- Making decisions about what to include and emphasize and what to drop;

- Organizing the content in a way that will help you to see the relationship among various elements so that you make decisions about objectives, materials, sequence and evaluation" (2000, p. 38).

However, in designing a language course, conceptualizing content is not an easy task. Experts in curriculum design (for example Graves, 2000; 1996; Richards, 2007; Brown, 1995; Nunan, 1988 Yalden, 1987; Dubin and Olishtain, 1987) agree that what to teach or what to focus on in a language course is a demanding task. This is because language teaching is a complex process (Richards, 2007) and is no longer viewed from only structural perspectives where the focus is mainly on grammar and vocabulary aspects. Rather, teaching language has been influenced by the recent approaches such as the communicative approach, the task-based approach, and the content-based approach, and the like (Graves, 2000; 1996; Richards, 2013, 2007; Brown, 1995; Dubin and Olishtain, 1987). For example, "The language content dimension has extended to include notional and functional meaning along with structures, situations, and themes" (Dubin and OLishtain, 1987, p.106). Moreover, socio-cultural, and psychological theories have to be taken into consideration along with pedagogical methods and procedures (Mckernan, 2008; Grundy, 1987; Pennycook, 1998).

\section{"What makes up the content of language learning?"}

Due to the complex nature of language, Graves encourages language teachers to adopt a practical framework of conceptualizing language content based on Stern's concepts. The framework is made up of three major categories: language, learning and learner, and social context. Below is a description of the three categories for conceptualizing the content adapted from Graves (2000).

The first category-focus on language- deals with the complex phenomenon of language that involves a variety of aspects such as linguistic skills, situations, topics, competencies, functions, tasks, speaking, reading, writing, listening, and genre (for further discussion see Graves, 2000).

The second category-focus on learning and learners-involves a. affective goals concerned with developing positive attitudes towards the target language and its culture, b. Interpersonal skills: are concerned with the skills that a learner should develop not only to promote learning but also to communicate with others in the classroom or outside the classroom, and c. Learning strategies that are concerned with how students learn. "They are the cognitive and metacognitive strategies we use to learn effectively and efficiently such as self-monitoring or developing strategies for remembering new vocabulary" (2000: 50). The aim behind these strategies is to help students develop learning at the classroom and beyond the c classroom level (Grundy, 1987).

The third category-focus on Social Context deals with aspects at the macro level, that is with aspects that are beyond classroom activities at the micro level. It involves three areas, sociolinguistic skills, sociocultural skills, and sociopolitical skills. The sociolinguistic skills are "context dependent'. As such they involve selecting and using the appropriate linguistic expressions, skills, as well as the "extra linguistic behavior" that have to be learned alongside 
situations. (Graves, 2000; Grundy, 1987, Pennycook, 1999).The sociocultural skills, on the other hand focus on understanding certain cultural aspects of identity, values, beliefs, and traditions such as the concept of social class or the discrepancy between men and women. This understanding is important since it helps learners to "interpret ...messages and behave and speak in a culturally appropriate way" (Graves, 2000, p. 51). The sociopolitical skills "involve learning to think critically and take actions for effective change in order to participate effectively in one's community" (p.51).

Categorizing the language areas in such a framework is like a guide that gives the teacher choices on what to involve in a course. However, Graves says that this is not "a map of everything you should include in your course" because there may be other categories and skills to add (2000, p.53).

\subsubsection{Guidelines and Factors for Developing Materials}

Within the scope of TESOL, it is essential for teachers to know how to develop their materials successfully. Fortunately, the literature on curriculum offers certain criteria, described in terms of checklists and principles, to be followed while selecting or developing the created materials which constitute the basis of teaching in classroom. At a course level, Cunningsworth (in Richards, 2007, p. 258) provides a checklist for evaluating a textbook such as "aims and approaches, design and organization, language content, skills, topics, methodology, teachers' books, and practical considerations". Likewise, Tomlinson (2003, p.21) presents a checklist of characteristics that good language teaching materials should have. Some of these characteristics are presented below:

"Materials should achieve impact.

Materials should help learners feel at ease.

Materials should help learners to develop confidence.

Materials should provide the learners with opportunities to use the target language to achieve communicative purposes.

Materials should take into account that learners have different learning styles.

Materials should not rely too much on controlled practice.

Materials should provide opportunities for outcome feedback."

However, Dudley-Evans and St. John (2004) state that it may not be practical for teachers to consider all those criteria while developing materials. Accordingly, teachers are recommended to select their materials on the basis of key principles. Among those principles are, a. whether the materials are motivating or not; $b$. to what extent the materials are aligning the learning objectives; and c. whether the materials support the learning process or not. Furthermore, Richards (2006) argues that the successful selection of materials mediates between theory of language (including the type of syllabus design) and contextual and situational considerations. Richards also argues that a teacher must not rely to a large extent on textbooks, and as such they must have a role in the selection and evaluation of materials. This is because textbooks seldom meet the needs of a particular context. In this respect, he suggests the idea of textbook adaptation that is adjusting a textbook in accordance with the demands and characteristics of a textbook. Practically, adaptation of a textbook can be applied through a variety of procedures like "Modifying content...Adding or deleting content...Recognizing content...Modifying tasks....Extended tasks" (Richards, 2007, p.260).

With regard to teacher's role in developing materials, the literature puts a great emphasis on this factor. Specialists in curriculum design encourage teachers to create their own materials or at 
least combine between textbooks and other sources of materials (Johansson,2006;Akbari and Razavi,2015;McGrath, 2013, 2002; Gilmore, 2007; Block, 1991; Clark, 1989). Block (1991) is in favor of teachers developing their materials which as he considers is merely one part of teachers' responsibilities. The teachers' role in developing their own materials involves taking decisions such as adaptation, suitability, and selection. The idea of encouraging teachers to develop their own materials has several advantages. Block (1991) and Richards (2007) have provided considerable discussion about this subject. Below is a brief summary of some advantages.

Contextualization- Teachers' decision of adaptation enables them to produce materials that are contextually suitable taking into consideration socio-cultural and political dimensions (Moghaddas, 2013; Blok, 1991; Graves, 2000; Richards, 2007). Richards (2007: 261) refers to this advantage in terms of "relevance" where materials are directly relevant to students and institutional needs and that reflect local content, issues, and concerns". Additionally, Block (1991, p. 216) stresses the purpose of reflection saying that "If we are to be reflective practitioners in the field of ELT, we need to consider all aspects of our teaching. I believe that preparing our own materials is one of these aspects".

Students' involvement- The new shift in pedagogy and curriculum design emphasizes the idea of involving students into the process of teaching and course design. In this respect, teacher's adaptation will enable him to produce materials that are responsive to students' needs and preferences. This will also help teachers avoid any the challenge of using courses that don't fit students' needs.

Avoiding challenges of textbooks-Some textbooks are produced for commercial and general purposes. In other words, they are not designed to serve specific purposes in a particular context. In this case, teachers' role in developing their materials serves avoids the inappropriateness or unsuitability of textbooks.

Flexibility- Materials developed by teachers in a particular institution "can be easily revised or adapted as needed" (Richards, 2007, p. 261).

\section{RESEARCH DESIGN}

Based on its purpose and aims, the study draws on the interpretive paradigm employing its epistemology and philosophy as an underpinning stance. Accordingly, the qualitative approach has been selected for determining the strategy and methods of sampling, and data collection and data analysis.

\subsection{Methodology}

In conjunction with the interpretivism paradigm underpinning this study, the case study has been chosen as a research strategy for the purpose of providing a framework for data collection and analysis (Bryman and Bell, 2007; Chapelle and Duff, 2003; Devers and Frankil, 2000; Esteberg, 2002). I understand that there are certain realities or strategies for conducting my qualitative research. However, based on epistemological and methodological considerations, the purpose, and questions of the study, the case study has been selected as the most appropriate strategy for this study.

The principal goal of this research is to explore teachers' perspectives and beliefs regarding the factors that may impact course design and in what way. The intention of the researcher behind that is to provide rich insights and develop multiple interpretations, patterns as an ontological 
stance (Guba and Lincoln, 1994; Smith, 2003). For this, I need to gather detailed and thick information from the participants about my case (Yin, 2009; 2005; 2003; Stake, 2000; 2005; Merriam, 2002; 1988).

\subsection{Teacher Sample}

In light of the interpretive approach and the qualitative methodology underpinning this cases study research, the sample of teacher participants has been purposefully selected(Dornyei, 2011; Punch, 2008; Miles and Huberman, 1994; Denzin and Lincoln, 2008; 1994). The teacher sample involves nine teachers who teach a variety of EFL/EAP courses at the undergraduate level. In spite of the differences in terms of gender and nationalities, the sample is homogeneous in the sense that all teachers had been selected from the same population- teachers working in the same context.

\subsection{Methods of data Collection}

The main source of data collection for this study is the semi-structured interviews that depend on open-ended questions set up within an interview guide (Kvale, 2006). The researcher followed a professional protocol including procedures of "thematizing" and "designing" the questions to be asked in accordance with the main research questions and purpose of study (Dorny, 2011, p. 173). The author met each participant individually and faced to face for one to two hours with short breaks. Every interview was recorded by a digital voice recorder. In addition, the author took notes in her notebook immediately after the end of the interview, particularly notes about the body language and whether the interviewee was interested or not (Cohen et al., 2000; Kvale, 2006, Kvale \& Brinkmann, 2009; Creswell, 2007; 2003).

\section{RESEARCH FINDINGS AND DISCUSSIONS}

\section{Factors Affecting Course Design from Participants' Perspectives}

This section presents in detail the findings emerging from the interview data. Two major findings have emerged, and they are organized in two sections: Student Factors and Departmental Factors. Also, the section presents a variety of emerging themes supported by the teachers' own words in the form of quotes from the interview transcript.In order to understand what factors that have the most impact on their EFL/EAP course design from the teachers' perspectives, all participants were asked several questions as indicated in the table below.

Table 1. Interview Guides

\begin{tabular}{|l|}
\hline $\begin{array}{l}\text { What Factors have the most Impact on designing EAP Courses at the College Level from the } \\
\text { Perspectives of Teachers? }\end{array}$ \\
\hline * What factors affect your course design? \\
\hline * How do these factors affect the courses you design? \\
\hline $\begin{array}{l}\text { * Do you face any challenges when you design your course? In what way } \\
\text { do these challenges affect your course design? }\end{array}$ \\
\hline * How do you handle challenges affecting course design?
\end{tabular}


It is striking that when teachers were asked to explore the factors informing design decisions, this was interpreted in terms of challenges and problems and there is no mention of positive factors. Nevertheless, there is a noticeable divergence in their identification of the sources of these factors. In response to the question 'How these factors affect course design?' The data show that they have three types of impacts. First, they have impacts on course design elements, particularly in relation to materials design, selection of topics, and preparing exams. Second, they have impacts on teachers by prompting them to be more responsive to the students' needs and desires. Third, such factors psychologically have negative impacts on teachers causing pressure, stress, and confusion (see Figure 2).

As to how teachers handle the problems, most of them stated that they are able to cope with these challenges based on their contextual expertise and beliefs. Practically, some of them provided certain helpful ideas that can be described in terms of a general category- Adaptation which makes two themes: teachers adapting courses and teachers adapting themselves.

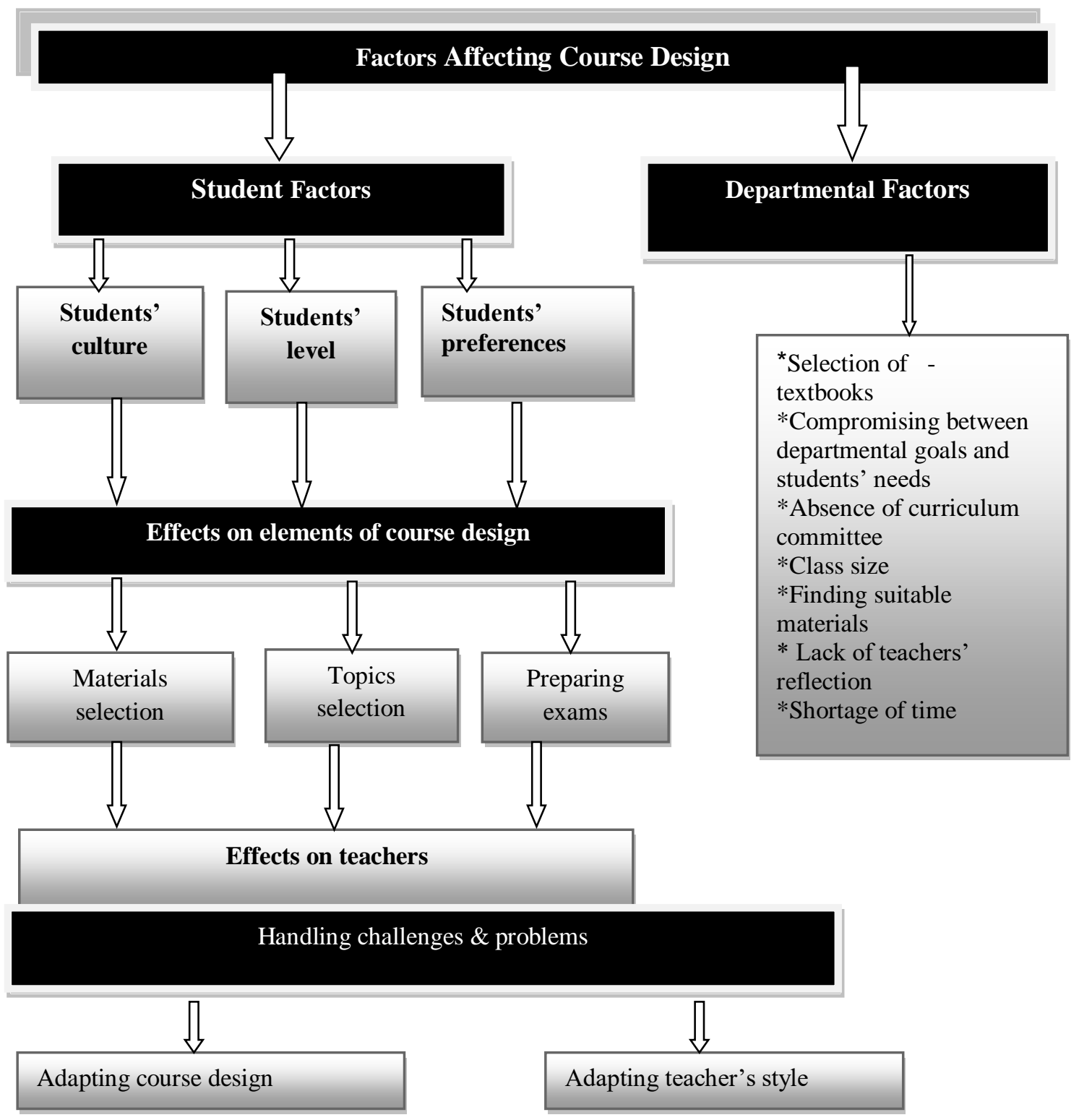

Figure 2. Factors Affecting Course Design 


\subsection{Student Factors}

In response to the category of 'student factors', the data show there are three types of analyses and as such they fall into three sub-categories. The first category is concerned with students' culture. The second category is concerned with students' linguistic level. The third category involves analyses in terms of students' preferences.

\section{Category One: Students Factor-Cultural Background}

Data analysis reveals that three teachers (A, C, and W) having different cultural backgrounds considered students' culture, that is different from their culture, as a challenging factor arguing that it negatively influenced designing courses. For example, participant (A) reported that analysed critically students' culture in terms of their attitude, narrow thinking, less interest in study, and their focus on getting grades. However, he could challenge this factor by taking important decisions such as modification and adaptation. Similarly, participant (W) reflected on his struggles with students in this context. He said that "they come to the classroom with their first language culture". He considered this as a problem creating "conflict between the teacher and students' cultures". In response to how he can deal with such a challenge, he said that he has to be aware in his selection of topics. He has to select the topics that are culturally suitable to the students.

This finding further raises two crucial issues. The first issue relates to the way these teachers see or understand their students' cultural background. The second issue relates to the impact of students' cultural background on the process of teaching inside and outside the classroom. In particular, this issue impacted three basic elements: exams, methodology, and the selection of topics and materials.

Based on this finding, we can also interpret that these teachers perceive the phenomenon of cultural differences as a serious challenge influencing the efficiency and effectiveness of course design. Therefore, they have been pressured with this issue considering it as a negative factor. They based their justification on the rationale that it affected the basic aspects in the development of a course, particularly methodology, content of a course, and methods of assessment. For example, participant (W) considered cultural difference as a limitation to course design reflecting on his struggling with selecting the topics that suit the students' culture in the classroom. Accordingly, he is not free in using authentic texts in the classroom which is particularly important for improving their speaking and pronunciation.

Generally, within the area of English language teaching, and especially after the spread of English as the global language, culture has become an essential aspect in EFL teaching. Atkinson $(1999$, o. 625) points out to the role of culture arguing that "Except for language, learning, and teaching, there is perhaps no important role in the field of TESOL than culture. Implicitly or explicitly, ESL teachers face it in everything they do". This implicates that teachers need to be aware of the concept of culture and the relevant aspects including the cultural difference between teachers and students (Atkinson, 1999, Duff and Uchida, 1997).

In spite of being confronted with this challenge, the teachers have attempted to be culturally aware of their students' needs in order to handle the issue of cultural difference and to bridge the gap between themselves and their students. This came through developing cultural awareness by understanding and identifying students culturally. Furthermore, they developed particular strategies such as the adjustment or adaptation of curriculum in accordance with students' needs, in general and students' culture in particular. For example, participant (W) decided to choose the topics that are suitable to students' culture. 


\section{Category Two: Student Factors-Linguistic Level}

The second challenge that emerged under the category of 'Student Factor' is described in terms of students' linguistic background. The data reveal that five teachers ( M, F, N, S, and W) reflected on their struggles with this challenge. They critically analyzed it in terms of several themes such as "students' low linguistic proficiency" (M), "students' low input" (S), and students' low pragmatic skills (S). For example, participant (S) negatively criticized the poor level of students' abilities in pragmatic understanding. Because of this, she tempted to prepare easy exams in order not to "fail the students". In order to solve the problem, she tries to balance the situation by being firm, selective, and fair as stated in her quote below.

Participant (F) referred to another serious challenge relating to the students' inability and low linguistic level to study English literature stating that "the problem is with the students. It is not easy to teach them literature as literature because the students are not qualified to study literature...In order to handle this situation, I have to adapt the course according to the students' level.

A fourth problem regarding students' linguistic level is provided by participant (M) reporting that "We develop our courses and we choose the material but when we come to the class, we discover that the students have no background". He argued that this factor has influenced the choice of materials. Instead of choosing materials that are suitable for college students, he is tempted to choose simple materials in order to satisfy the simple level of students.

The majority of teachers reflected on their struggles with teaching students with a range of abilities in studying courses designed for a particular tertiary level. The problem is that not all students are placed according to their English proficiency level. The negative effects of this problem were observed in every stage of course design, particularly the selection of the course content, material design, methodology, and even the selection of courses, as has been argued by participant $(F)$. This finding raised a crucial issue that must be taken into consideration when designing EAP/EFL courses at the higher education level. The issue concerns the relationship between students' language proficiency, their academic achievement, and course design.

In this case, teachers feel the need to moderate their planning to accommodate lower levels of proficiency. Accordingly, teachers made a decision of adaptation in all stages of course design in order to adjust the course to those students with English low proficiency. Overall, the idea of adapting the course in terms of simplicity and flexibility raises a crucial issue relating to the proficiency of curriculum design at the higher education level. Rationally, adapting or modifying the EAP courses in accordance with the low level of students' language proficiency is a challenge as it leads to designing EAP courses that don't meet the recent requirements of globalization and modern technology. Recently, the sector of higher education in many countries has witnessed certain developments and reformations in order to meet the requirements of the globalization and the modern technology (Diamond, 2008). Diamond focuses on preparing students for future careers pointing out that "Business and industry leaders increasingly call for graduates who can speak and write effectively, have high-quality interpersonal and creative thinking skills... and can work effectively with individuals from different cultures and background" (2008, p.x). Due to the status of English as the global language, the field of TESOL has undergone certain changes across all its aspects, curriculum development, classroom methodology, teacher development and students' assessments. Accordingly, a new pedagogical model is needed to accommodate the case of English as a means of international and intercultural communication" (Alptekin, 2000, p.63). This requires further development and updating EAP curriculum or course design in order to enable learners to use language effectively for the purposes of study and future careers. 


\section{Student Factors-Students' Preferences}

The third category of challenges can be described in terms of students' preferences (what they like and dislike). In this regard, four teachers ( $\mathrm{M}, \mathrm{N}, \mathrm{R}$, and $\mathrm{W})$ criticized what their students like. First, participant $(\mathrm{N})$ reported that students are mostly not responsive to the materials that he had worked hard to prepare causing stress and confusion to the teacher. To solve this problem, the teacher has to be both realistic-by predicting the worse- and creative-by creating a supporting plan. The excerpt below demonstrates this challenge.

A second challenge in this respect is due to students' focus on high marks. Three participants (A, $\mathrm{M}, \mathrm{S}$ and $\mathrm{W}$ ) complained about this issue. Participant (M) said that "The students are so much concerned about the marks". Accordingly, he has to be "more tolerant, lenient, and more generous in giving marks", otherwise he will not find students registering for his sections. Likewise, participant (W) suffers from this phenomenon when he said that "All the students want full marks". Definitely, this problem has its effects on exams. However, the teacher has solved this issue by preparing exams that are suitable for the majority of students and by giving "some items that are challenging and that can only be answered by the good students".

The third challenge under this category is due to students' focus on memorization rather than understanding. Two participants ( $\mathrm{R}$ and $\mathrm{S}$ ) raised this issue reporting that "Our students don't read by their own. They read something to memorise". (R). Participant (S) associates this problem with the exam since the students don't express their opinion, particularly in writing courses.

Students' preferences are considered as a major challenge for teachers in this context. Although teachers pointed out that they take into account all kinds of students' needs, the objective as well as the subjective, in reflecting on their challenges, they showed their dissatisfaction with some preferences of students. The hardest challenge, in this regard was due to the students' focus on getting high marks and certificates with little attention on learning and academic growth. A second criticism of students' preferences was directed to students' focus on memorization more than the focus on analysis and critical thinking. The teachers considered such preferences as challenges because they enforced them to design courses that are beyond the college level of students. Moreover, they influenced even the policy and style of teachers pushing them to behave in a way that contradicts their professional beliefs and experiences.

Students' interest is one of the basic aspects within the concept of students / learners' needs (Graves, 2000; Richards, 2007, Dudley Evans and ST. Johns, 2004). According to Graves, learners' interests involve "What kinds of the topics or issues they are interested in? What kinds of personal and professional experience they do? The importance of taking into account this information about students' interests is "to help teachers to gear the course towards students' experience and interests" (2000, p. 103). The finding of students' interests raises a crucial issue concerning what is called "objective information" and "subjective information" about students (Brindely, Nunan, in Graves, 2000, p. 104). Objective information involves facts about students such as their language level and what they need they course for, while subjective information involves attitudes and expectations in relation to what and how they will learn. Graves recommends teachers who are involved in designing their courses to take into consideration both kinds of information, objective as well as subjective. In this case, she says that" I feel it is crucial to find out about their interests and backgrounds and to build the syllabus around the information, so they will be engaged" (2000, p. 105). 


\subsection{Departmental Factors}

The second main category in this section involves factors that are ascribed to the policy and regulations at the departmental and institutional levels. From this category, a number of themes emerged that can be described in terms of different challenges. Below is a list of these themes:

- Selection of textbooks

- Compromising between departmental goals and students' needs

- Absence of curriculum committee

- Class size

- Finding suitable materials

- Lack of teachers' reflection

Selection of textbooks-the data reveals that the selection of topics constitutes the most influential challenge. In general, their issue is based on the belief that the textbooks used for some courses are difficult, unsuitable and "not convincing" according to the level of students (S). For example, participant (L) complained that the textbook that she was given to teach advanced communication "is for business communication...it is not for students majoring in English".

Compromising between the department's needs and students' needs-The second challenge is highly serious since it reflects the struggles of some teachers (like A, N, and S) who try hard "to compromise between the department and the students" (N). Participant (W) agreed with (N) in this issue saying that "it is so hard to satisfy the department and the students... There are some boundaries... We have mismatching between the students' expectations and the course's goals, content, and materials". A similar example for this challenge is provided by participant (A) who was also challenged with the conflict between the department's goals and the students' goals or expectations. His struggle is expressed in the few words below:

The department...demands goals. Their goals are different from the students' goals. I am between satisfying my students, satisfying my department, and satisfying myself... here the problem is that teachers cannot go beyond the learning objectives ... You are free within the framework. You cannot go beyond that one.

Absence of curriculum committee-The third challenge is related to the absence of a specialized curriculum committee that is supposed to provide guidance to teachers. This issue was raised by two teachers (M and $\mathrm{S}$ ) who pointed out that there is no representation of linguistic courses to make justify, adapt, and develop courses according to student needs and institution expectations. Additionally, two participants ( $\mathrm{F}$ and $\mathrm{M}$ ) mentioned a third problem relating to the department curriculum which is offering many literature courses that are beyond the needs of our students. They draw on the rationale that the students need courses that improve their skills of communication rather than literary knowledge.

Finding suitable materials-This is the fourth challenge mentioned by one participant (S). In an attempt to reflect on her struggles with this challenge, she said that:

There are challenges like finding the suitable materials... most of the materials I use are not suitable. They are above the level of the students... In fact, it is very difficult to find suitable material...sometimes it is difficult to adapt it to my students... If it is designed by an expert, it is a piece of cake. 
Lack of teachers' reflections is a fifth challenge that was considered by participant (S). Her criticism involves both her colleagues and the work context. For this she said "We don't have the chance of sitting together with our colleagues to discuss many things. ... The educational environment is not challenging".

\section{CONClusion}

This case study aims to explore the factors that affect the process of designing English courses at the undergraduate level in a college context from the perspectives of teachers who design their courses. Data analysis explored a range of challenges that teachers face when designing EAP/EFL courses and how these challenges negatively impact the process of course development. The teachers identified and critically analyzed several challenges that can be categorized in terms of their sources into two sets: 'Student Factor' and 'Institution Factor', each with several implications.

Identification and diagnosis of factors have raised a number of implications that can be organized into two sets based on the type of factors or challenges. The first set of implications concerns 'Student factor'. The first implication concerns course design as portrayed by Nation and Macalister (2010) is a process composed of an inner circle including learning elements that are surrounded by an outer circle including a range of influential factors. This suggests that teachers who are engaged in course design must be aware of the surrounding factors and how they affect the process (Carl, 2005). Also, taking into account all influential factors helps teachers save troubles and manage the situation (Graves, 2000; 1996). However, identification or description of the factors is not is not effective unless it is integrated with the process of problematization of the situation. Basically, problematizing the situation involves diagnosing and managing problems. With regard to course design, problematizing the situation requires making decisions such as adaptation of materials, flexibility in syllabus design, modification of activities, and the like as teachers act in this case study.

A second implication that teachers need to be aware of concerning students' preferences is the objective and subjective needs of students as Graves refers which is crucial for teachers when designing their courses. Taking all information about students into account helps teachers to build up their courses in a way that engages students in the process of learning (Graves, 2000). The third implication concerns designing EAP/EFL courses in a way that improves students' cultural competence which in turn enables students to meet the goal of using English effectively and fluently. Teachers can solve the problem by several strategies to be adopted at the methodological level and the selection of teaching materials and topics. In this respect, Peterson and Coltrance (in Al-Issa, 2005, p. 159) suggest that "culture must be fully incorporated as a vital component of language learning" since "students can be successful in speaking a second language only if cultural issues are an inherent part of the curriculum".

The second set of implications concerns the second category of teachers' challenges that are institutional or departmental. Based on teachers' suggestion that they need guidance and support at the department and institution level, the faculty is recommended to establish a curriculum committee concerned with several issues. First, at the curriculum level, it is recommended that 1. the members of the local committee must collaborate with experts in English language curriculum to determine what courses to offer to the students that satisfy the goals and expectations of the department and students; 2. there must be a careful statement of goals and learning objectives in order to meet students' needs and expectations in accordance with the recent trends of education; 3. there must be frequent discussion between teachers and the members of the committee regarding the selection and articulation of the course components; 4 . 
there must be a complete survey about the needs analysis at all levels: culture, language proficiency, cognitive abilities, preferences, psychology, as well as others (Dudley-Evans and ST. John, 2004; Richards, 2007).

Second, the committee should set up a statement of policy of students' admission. Students who enroll the college must gain a minimum score in IELTS or TOEFUL in order to cope with the courses that are designed in English and communicate with teachers who are mostly not Arabs. Furthermore, students must be placed into hierarchical levels according to their proficiency of English such as level one for beginners, level two for average students, and level three for advanced students.

Third, the committee should work in collaboration with the Ministry of Higher Education or other tertiary institutions in order to provide programs of professional development that are tailored for the specific needs of the context where the study takes place. The purpose of those programs is to provide teachers with workshops and seminars that are concerned with issues relating to designing EAP/ESP curriculum or courses. For example, teachers need to know issues such as adaptation, integration, and alignment in articulating elements like materials and course content. These programs are also important for establishing "a community of practice" as suggested by Lave and Wenger (1991) in this context. Establishing a community of practice is a helpful idea for teachers sharing the same concerns and goals to meet frequently in order to exchange their views and reflections regarding curriculum design.

The idea of teachers' orientation and guidance at the faculty and department levels is also supported by Graves and other specialists in education who suggest that "teacher involvement is critical to the success of a curriculum, but teachers cannot alone and by their own create and sustain it. Both research and practice emphasize the importance of TOP-DOWN and BOTTOM UP processes as essential for curriculum development and innovation" (Markee, Stoller, , Wu, Rice, in Graves, 2008, p. 175).

\section{Limitations OF STUDY}

This research study has fulfilled the purpose of exploring teachers perspectives regarding the factors that affect the process of course design and how. Data analysis a considerable number of findings that help identify and diagnose the factors affecting course design in this context. Based on these factors, several implications have been raised that may be of a great value for those who are concerned with course design withing the area of TESOL. However, since it is a case study research, the findings cannot be generalizable. Thus, it is recommended that the limitations of the study can be considered in order to conduct further research concerned with examining every aspect and component of course design from the perspectives of teachers and students in this context and other TESOL contexts.

\section{REFERENCES}

[1] Abdel-Jawad, H.R. \& Abu Radwan, A.S. (2011). The status of English in Institutions of Higher Education in Oman: Sultan Qaboos University as a Model. In A. Al-Issa and L.S. Dahan (Eds.), Global English and Arabic: Issues of language, culture and identity (31, pp.123-151). Oxford: Peter Lang.

[2] Akbari, O. \& Razavi, A. (2015). Using authentic materials in the foreign language classrooms: teachers' perspectives in EFL classes. International Journal of Research Studies in Education,18,1-12.

[3] Al-Issa, A. (2006). The cultural and economic politics of English language teaching in Sultanate of Oman. Asian EFL Journal,8, (1),194 -18. 
[4] Al-Issa, A. (2007). The implications of implementing a flexible syllabus for the ESL policy in the Sultanate of Oman. RELC Journal, 38, (1),199-215.

[5] Al Jadidi, H. (2009). Teaching English as a Foreign Language in Oman: An exploration of English Language Teaching Pedagogy in Tertiary Education. Unpublished PhD. Dissertation. Victoria University, Melbourne, Australia.

[6] Al-Jardani, K. S.S. (2012). English Language Curriculum Evaluation in Oman. International Journal of English Linguistics, 2 (5), 40-44.

[7] Apple, M. (1990). Ideology and curriculum. New York: Routledge.

[8] Atkinson, D. (1999). TESOL and culture. TESOL QUARTERLY, 33 (4), 625-634.

[9] Block, D. (1991). Some thoughts on DIY materials design. ELT Journal, 45, (3), 211-217.

[10] Borg, M. (2001). Key concepts in ELT. Teachers' beliefs. ELT Journal, 55 (2) 186-188.

[11] Brindley, G. (1989). The role of needs analysis in ESL program design. In R.K. Johnson (Ed.), The Research Language Curriculum, (PP. 63-78). Cambridge: Cambridge University Press: 63-78.

[12] Brown, J. D. (1995). The Elements of language curriculum. New York: Heinle and Heinle.

[13] Bryman, A. \& Bell, E. (2007). Business research methods. Oxford: Oxford University Press.

[14] Chapelle, C. \& Duff, P. (2003). Some guidelines for conducting quantitative and qualitative research in TESOL.TESOL QUARTERLY, 37(1), 157-177.

[15] Carl, A. (2005). The "voice of the teacher" in curriculum development: A Voice crying in the wilderness? South African Journal of Education, 25 (4), 223-228.

[16] Carroll, M. \& Palermo. (2006). Increasing national capability for quality higher education: The Case of Sultanate of Oman.

[17] Clark, D. (1989). Materials adaptation: why leave it all to the teacher? ELT Journal, 43 (2), 133-141.

[18 Cohen, L., et al. (2000). Research methods in education. (5th edition). London: Routledge Falmer.

[19] Creswell, J. W. (2007). Qualitative inquiry and research design: Choosing among five traditions. Thousand Oaks, CA: Sage.

[20] Creswell, J. W. (2003). Research design: Qualitative, quantitative, and mixed methods approaches. (2nd ed.). Thousand Oaks, CA: Sage.

[21] Denzin, N.K. and Lincoln, Y.S. (2008). The Discipline and practice of qualitative research. In N.K Denzin \& Y.S. Lincoln. (Eds.). The Sage Handbook of Qualitative Research. (PP. 1-33). Thousand Oaks: Sage.

[22] Devers, K \& Frankel, R. (2000). Study design in qualitative research: Sampling and data collection strategies. Education for Health, 13(2), 263-271.

[23] Dornyei, Z. (2011). Research methods in applied linguistics. Oxford: Oxford University Press.

[24] Dubin, F \& Olshtain, O. (1987). Course design: Developing programs and materials for language learning. Cambridge: Cambridge University Press.

[25] Dudley Evans \& St. John. (2004). Developments in English for Specific purposes: A multidisciplinary approach. Cambridge: Cambridge University Press.

[26] Duff, P. (2008). Case study research in applied linguistics. New York: Routledge.

[27] Diamond, R.M. (2008). Designing and assessing courses and curricula: Practical guide. (3rd ed.). San Francisco: Jossey-Bass.

[28] Esterberg, K.G. (2002). Qualitative methods in social research. McGraw-Hill Companies.

[29] Fatihi, A. (2003). The Role of needs analysis in ESL program design. South Asian Language Review, 13 (1), 39-59.

[30] Fink, L.D. (2003). A Self directed guide to designing for significant learning. San Francisco: JosseyBass.

[31] Fink, L.D. (2007). The Power of course design to increase student engagement and learning. Winter, PP. 13-17.

[32] Fink, L. D. (2009). Designing Courses for significant Learning: Voices of Experience: New Directions for Teaching and Learning. Willley Periodicals, Inc.

[33] Fink, L.D. (2013). Creating significant learning experiences: An integrated approach to designing college courses. New York: John Wiley and Sons.

[34] Gilmore, A. (2007). Authentic materials and authenticity in foreign language learning. Language teaching, 40 (2), 97-118.

[35] Graves, K. (1996). Teachers as course developers. Cambridge: Cambridge University Press.

[36] Graves, K. (2000). Designing language courses: A guide for teachers. London: Newbury House Teacher Development. 
[37] Graves, K. (2008). The language curriculum: A social contextual perspectives. language teaching, 41(2), 147-181.

[38] Grundy, S. (1987). Curriculum product as praxis. London: The Palmer Process.

[39] Guba, E.G., \& Y.S. Lincoln. (1994). Competing paradigms in qualitative research. In N.K. Denzin and Y.S. Lincoln. (Eds.). Handbook of qualitative research, (PP.105-117). Thousand Oaks, CA: Sage.

[40] McDonald, C. (2006). Challenging social work: The Institutional Context of Practice. New York: Macmillan.

[41] McDonough, J., Shaw, C. \& Masuhara, H. (2013). Materials and methods in ELT. A teacher's guide, Oxford, Blackwell Publishers.

[42] McGrath, I. (2002). Materials evaluation and design for language leaching. Edinburgh: Edinburgh University Press.

[43] McGrath, I. (2013). Teaching materials and the roles of EFL/ESL teachers: Practice and theory. London: Bloomsbury.

[44] McKernan, J. (2008). Curriculum and imagination: Process, theory, pedagogy, and action research. New York: Routledge.

[45] Merriam, S.B. (1998). Qualitative research and case study applications in education. San Francisco: Jossey-Bass.

[46] Merriam, S. B. (2002). Qualitative research in practice: Examples for discussion and analysis. San Francisco: Jossey-Bass.

[47] Miles, M. B. and Huberman, A. M. (1994). Qualitative data analysis: An Expanded Source Book. Thousand Oaks, CA: Sage.

[48] Miles, M.B., Huberman, A.M., and Saldana, J. (2013). Qualitative Data Analysis: A Methods Sourcebook. Los Angeles: sage.

[49] Moghaddas, B. (2013). The effect of contextualization on the Iranian EFL learners' performance in reading tasks. International Journal of Education Science and Research, 3 (2), 11-20.

[50] Nation, I.S.P., \& Macalister, J. (2010). Language curriculum design. New York: Routledge.

[51] Nunan, D. (1988). The Learner- centered curriculum: A study in second language teaching. Cambridge: Cambridge University Press.

[56] Pennycook, A. (1999). Critical approaches to TESOL. TESOL QUARTERLY, 33 (3), 329-348.

[57] Punch, K. (2008). Introduction to research methods in education. Los Angles: SAGE.

[58] Richards, J. .C (2006). Materials development and research-making the connection. SAGE Publications, 37 (1), 5-26.

[59] Richards, J. C. (2007). Curriculum development in language teaching. Cambridge: Cambridge University Press.

[60] Richards, J. C. (2013). Curriculum approaches in language teaching: Forward, central, and backward design. RELC Journal, 44 (1), 5-32. Richards, K. (2003). Qualitative inquiry in TESOL. London: Palgrave Macmillan.

[61] Smith, J.A. (Ed.). (2003). Qualitative Psychology: A practical guide to research methods. Thousand Oaks, CA: Sage.

[62] Stake, R. E. (2000). The Case study method in social inquiry. In R. Gomm, M. Hammersley, and P. Foster. Case Study Method. (pp.17-27). London: Sage Publications Inc.

[63] Stake, R. E. (2005). Qualitative case studies. In N. K. Denzin, \& Y.S. Lincoln (Eds.), The Sage handbook of qualitative research. (pp. 443- 466). Thousand Oaks, CA: Sage.

[64] Tomlinson, B. (2003). Materials evaluation. In Tomlinson, B. (Ed.), Developing Materials for

Language Teaching, (pp.15-36). London: Continuum Press.

[65] Toohey, S. (2002). Designing courses for higher education. Philadelphia: The society for research into higher education and open university press.

[66] Whetten, D A. (2007). Principles of effective course design: What I wish I had known about learningcentered teaching 30 Years ago. Journal of Management Education, 31 (3), 339-357.

[67] Yalden, J. (1987). Principles of Course design for language teaching. Cambridge: Cambridge University Press.

[68] Yin, R. K. (2003). Applications of case study research (2nd edition.), Thousand Oaks, CA: Sage.

[69] Yin, R.K. (Ed.). (2005). Introducing the world of education. A case study reader. Thousand Oaks: Sage.

[70] Yin, R. K. (2009). Case study research: Design and methods (4th edition.), Thousand Oaks, CA: Sage. 